\title{
Probabilistic assessment of leachate propagation in the groundwater by an uncontrolled landfill
}

\author{
M. Pacheco \& J.F. Vasconcellos \\ UERJ - Universidade do Estado do Rio de Janeiro, Brazil
}

\begin{abstract}
This paper presents the probabilistic assessment of the maximum distance travelled by the contamination plume produced by the Municipal Landfill of São Pedro da Aldeia, State of Rio de Janeiro, Brazil. Field and laboratory results of ionic concentrations of several contaminants found in the groundwater adjacent to the landfill are presented and interpreted. The landfill has been in operation for 15 years with no concern regarding environmental protection, causing severe damage to flora, wildlife and local farmers. The main objective of this paper is to assess the environmental hazard to the surrounding properties by estimating the maximum distance travelled by the leachate plume by means of proper statistical interpretation of the measured ionic concentration of several contaminants.
\end{abstract}

Keywords: leachate, landfill, ionic concentrations, contamination plume.

\section{Introduction}

The beach town of São Pedro da Aldeia is located $150 \mathrm{~km}$ to the North of the City of Rio de Janeiro. The landfill takes $22.000 \mathrm{~m}^{2}$ and is located only $2 \mathrm{~km}$ from the closest urban district. The landfill gathers about 18.000 tons/year from the local population, in addition to 4.000 tons/year produced seasonally by the tourist population in summer, totaling 22.000 tons/year of solid waste. Tourism and land farming are the most important local economic activities. Several farms are located adjacent to the landfill, comprising about 1.000 inhabitants that use the ground water for personal use and land farming activities. Unfortunately, the criteria for selection of the municipal landfill did not meet the most basic environmental requirements, while the solid waste has been damped without any previous engineering design, causing severe environmental problems to the local 
population. This inadequate landfill operation demanded a thorough investigation on the impact produced by the leachate plume in the groundwater, as the local farms request compensation to the municipality for the environmental damage to their properties. This problem brought the opportunity to investigate the extent of the contamination of the groundwater, allowing drawing important practical conclusions regarding the maximum distance reached by the contamination plume. A thorough chemical investigation of the contamination produced by the landfill is found in [1].

\section{Measured ionic concentrations}

The local soil profile consists of an upper thin layer of coluvial sediments, about 1-2 m thick. A layer of young sandy silt residual soil is found below the superficial sediments. The thickness of the residual soil ranges from 1-2 meters (close to the landfill) to 6-7 meters (at more then $100 \mathrm{~m}$ from the landfill). The saturated horizontal hydraulic conductivity of the residual soil is estimated as $k_{h}=2$ to $3 \mathrm{~cm} / \mathrm{s}$. The hydraulic conductivity is estimated by numerical analysis by taking into account the time some contaminants take to reach the monitoring wells [2]. The permeable residual soil provides an overall preponderance of advective flow over dispersive flow. Also, significant loss of contaminant mass is enhanced by sorption and microbiological activity. Significant ionic concentrations of $\mathrm{Cl}^{-}, \mathrm{K}^{+}, \mathrm{Na}^{+}, \mathrm{Ca}^{+2}, \mathrm{Ba}^{+2}, \mathrm{HCO}_{3}^{-}, \mathrm{Fe}$ (total), $\mathrm{Mg}^{+}$, and $\mathrm{NH}_{4}^{+}$ have been measured at monitoring wells located at increased distances from the landfill, as shown in table 1. Well W9 (420 m away from the landfill, labeled background well) was assumed to be far enough from the landfill and as such was selected to collect samples to determine the background (uncontaminated) concentrations. This assumption proved to be valid, according to the analysis presented in this paper.

Table 1: $\quad$ Location of the monitoring wells [1].

\begin{tabular}{|c|c|c|c|c|c|c|c|c|c|}
\hline \multicolumn{8}{|c|}{ Distance of the monitoring wells to the landfill (m) } \\
\hline Well & W1 & W2 & W3 & W4 & W5 & W6 & W7 & W8 & W9* \\
\hline Distance landfill (m) & 22 & 32 & 44 & 72 & 74 & 135 & 151 & 230 & 420 \\
\hline
\end{tabular}

* background well.

The ionic concentrations in each well were measured according to 8 different time periods: February 2000, April 2000, June 2000, September 2000, February 2001, April 2001, August 2001 and September 2001. According to the procedure used to collect the water samples from the wells [3][4], the measured concentrations are referred as mean readings representing a given well at a particular time. Ionic concentrations of $\mathrm{Cr}$ (total), $\mathrm{Ni}^{+2}, \mathrm{Cu}^{+2}, \mathrm{Cd}^{+2}, \mathrm{Hg}^{+2}, \mathrm{Zn}^{+2}$, $\mathrm{Sn}^{+4}$ and $\mathrm{Pb}^{+2}$ have also been measured, showing however zero or near zero readings. 
Numerical predictions based on the solution of the differential equation of advective-diffusive flow did not provide conclusive results regarding the maximum distance reached by the contamination plume, mainly due to difficulties in modeling the loss of contaminant mass by sorption and microbiological activity [2]. Highly scattered ionic concentrations have been observed close to the landfill $\mid($ less than $100 \mathrm{~m})$. The scattered values are credited to $i$ - seasonal variations in rain intensity; $i i$ - changes in the composition of the solid waste and iii- inexistence of a draining system to collect the leachate; $i v$ small thickness of the pervious soil stratum close to the backfill.

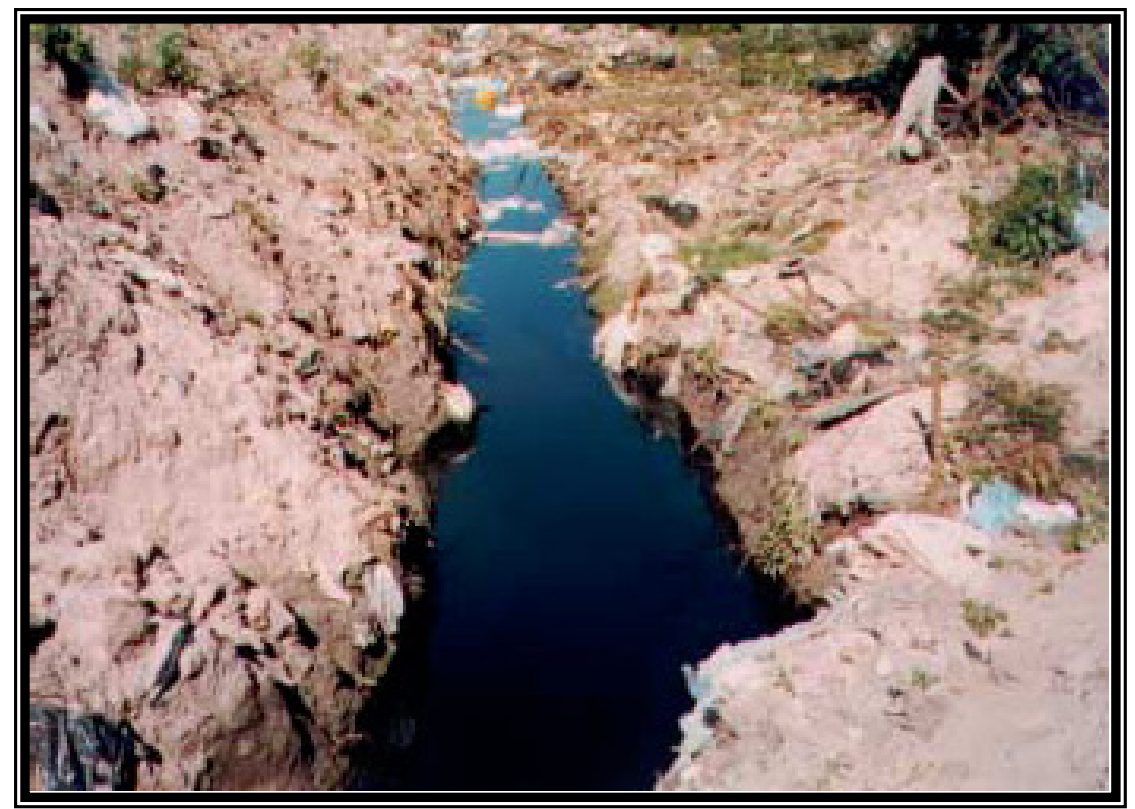

Figure 1: $\quad$ Trench at the landfill toe [1].

The leachate is collected partially by a trench excavated along the landfill toe, as shown in fig. 1 and 2. The trench is indicated by the number 1 in fig. 2 . The trench drains into the natural ditch shown by the number 2 in fig. 2 . The leachate leaks over the natural ditch for about $100 \mathrm{~m}$, and then progresses mostly underground, guided by the natural ditch. Two natural ponds are formed downstream by the ditch. The ponds are located $135 \mathrm{~m}$ and $230 \mathrm{~m}$ from the landfill, respectively. The ponds, used for animal consumption, were not contaminated before the landfill operation. Today the ponds are contaminated as a result of inadequate disposal of the solid waste. The leachate leak in the first $100 \mathrm{~m}$, as well as the small thickness of the soil for about the same extent, is probably the main reason for the scatter of the concentration readings close to the landfill. As a result, the monitoring wells located less than $100 \mathrm{~m}$ from the landfill become more sensitive to seasonal variations of rain intensity and solid 
waste composition. Based upon the measured ionic concentrations, the main objective of this paper is to determine the safe distance $d_{b}$ (fig. 2) beyond which the groundwater is no longer affected by the leachate contamination.

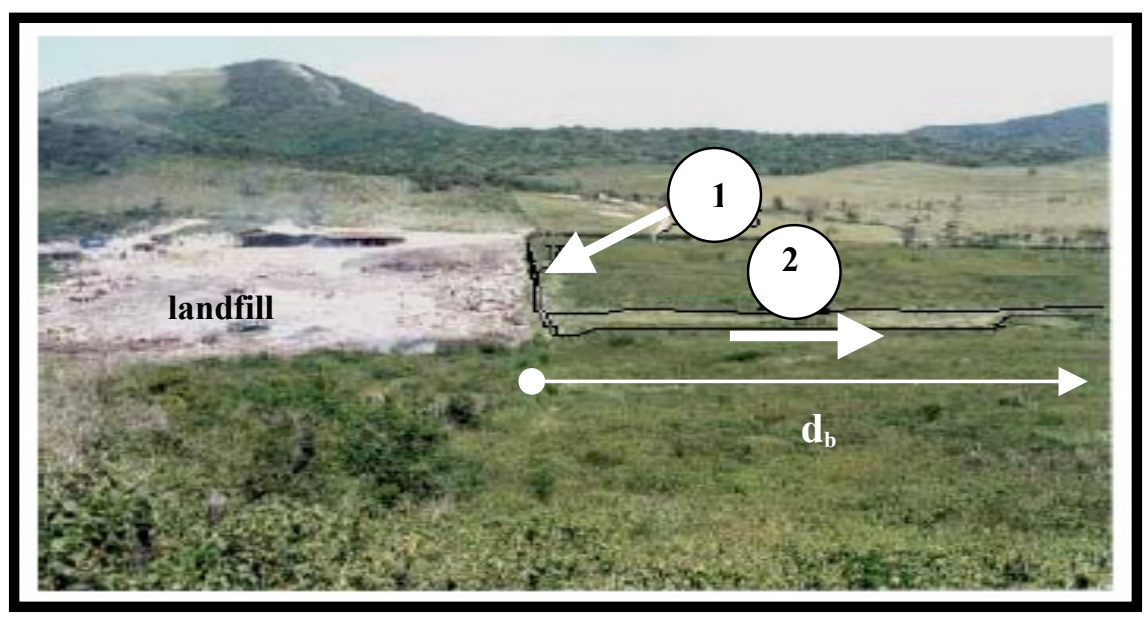

Figure 2: $\quad$ General view of the landfill [1]

Fig. 3 shows the variation (in time and distance) of the concentration readings for the ion $\mathrm{Cl}^{-}$. The $\mathrm{Cl}^{-}$concentrations are reasonably constant at the wells located more than $100 \mathrm{~m}$ from the landfill, with no trend to increase with time. This indicates that the contamination is practically stationary and therefore the plume is not propagating further downstream.

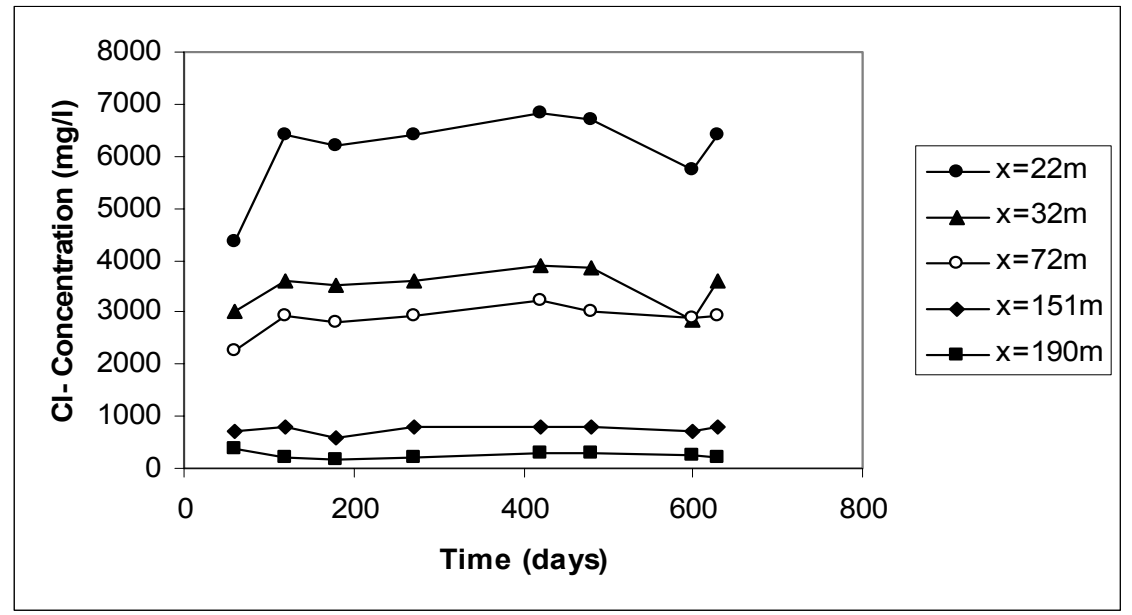

Figure 3: Variation of $\mathrm{Cl}^{-}$concentrations. 
In contrast, the readings may undergo significant variation with time at the wells located less than $100 \mathrm{~m}$. In spite of the fluctuations, the readings in this region also show a nearly stationary trend, confirming that the plume has already reached a stationary flow.

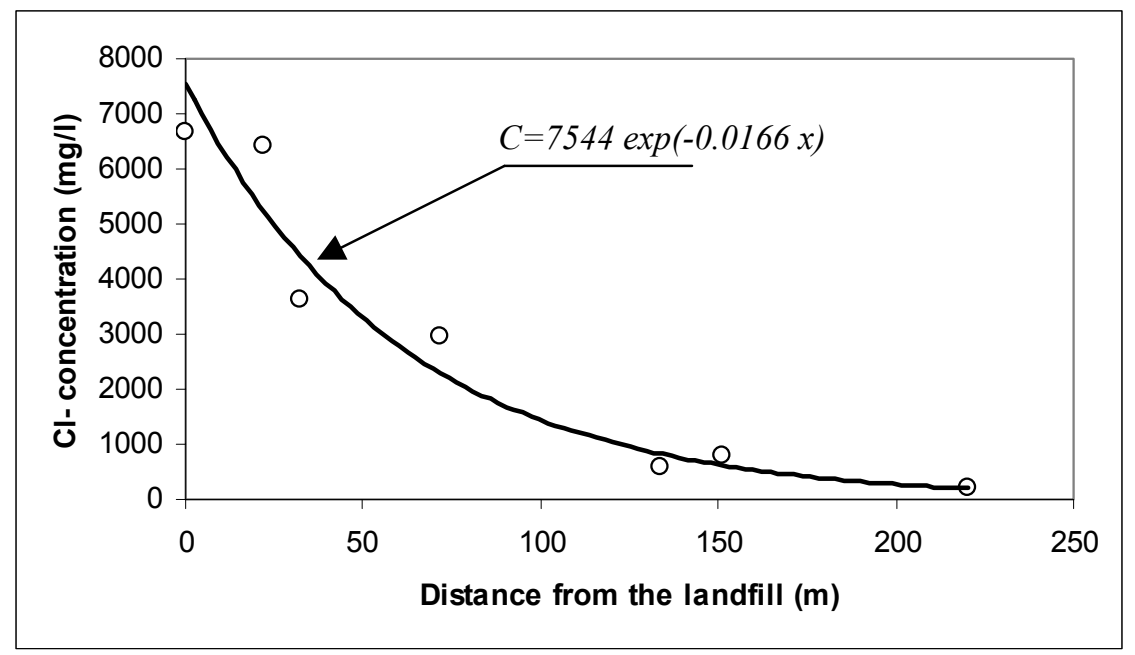

Figure 4: $\quad$ Sample $\mathrm{Cl}^{-}$concentrations in April 2000.

Fig. 4 shows that the variation of the $\mathrm{Cl}^{-}$concentration can be approximated by an exponential trend line of the type:

$$
C=C_{o} \exp (-b x)
$$

$C_{o}=7544 \mathrm{mg} / \mathrm{l}$ represents the initial mean concentration, whereas $b=0.0166$ $\mathrm{mg} / \mathrm{l} / \mathrm{m}$ represents the mean concentration decay per unit length. The regression constants $C_{o}$ and $b$ in fig. 4 are mean values representing the sample $\mathrm{Cl}^{-}$readings taken in April 2000.

Fig. 5 shows all $\mathrm{Cl}^{-}$concentration readings in the same plot (February 2000, April 2000, June 2000, September 2001, February 2001, April 2001, August 2001 and September 2001). Therefore, the regression constants $C_{o}=7192 \mathrm{mg} / \mathrm{l}$ and $b=0.0157 \mathrm{mg} / \mathrm{l} / \mathrm{m}$ in fig. 5 are regarded as mean values representing the population of ionic $\mathrm{Cl}^{-}$concentrations. The individual confidence limits in fig. 5 represent a margin of error $\alpha=5 \%$. The confidence limits show that the variance of the mean concentration $C$ decays exponentially for increasing $x$ values. This is discussed in more detail in the next session. A similar pattern is also observed in all other ionic concentration readings. 


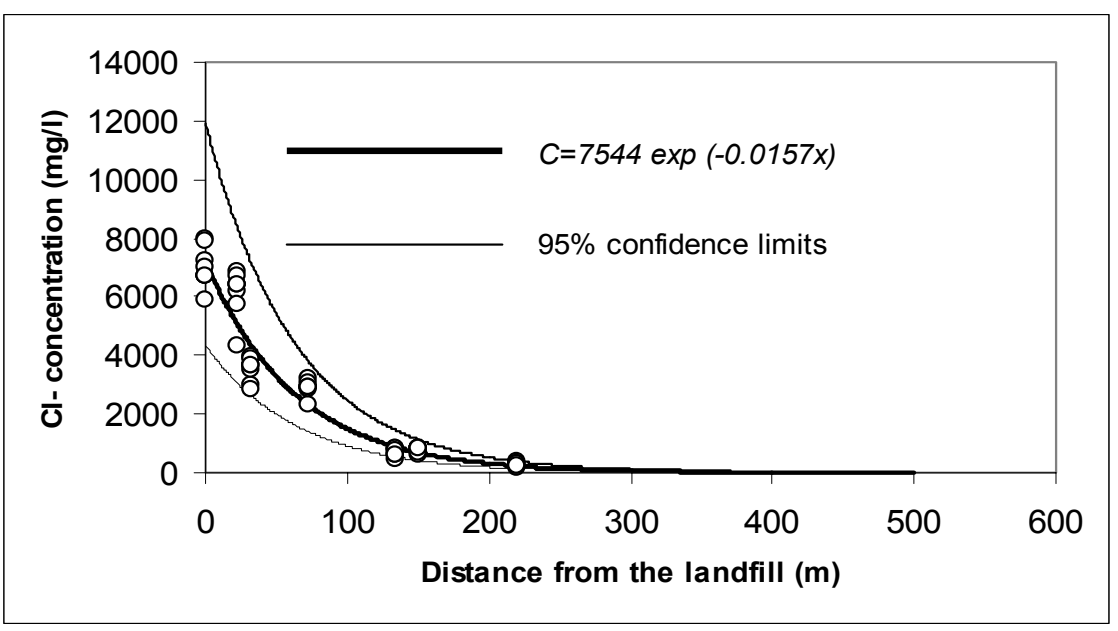

Figure 5: Concentration values representing the population of $\mathrm{Cl}^{-}$readings.

\section{Maximum distance travelled by an ion}

The exponentially decaying variance $V[C]$ in fig. 5 is estimated from eqn. (1), using FOSM approximation and assuming statistical independence between the regression constants $C_{o}$ and $b$ as [5]:

$$
V[C] \cong\left(\frac{\partial C}{\partial C_{o}}\right)^{2} V\left[C_{o}\right]+\left(\frac{\partial C}{\partial b}\right)^{2} V[b]
$$

Carrying out the derivatives, the exponentially decaying variance is expressed as:

$$
V[C] \cong \exp \left(-2 b x_{i}\right)\left(V\left[C_{o}\right]+x_{i}^{2} C_{o} V[b]\right)
$$

Statistical independence between $C_{o}$ and $b$ is explained by the fact that the initial concentration $C_{o}$ depends on the composition of the landfill, whereas the rate of concentration decay $b$ depends on the soil sorption and microbiological decay characteristics. The variances $V\left[C_{o}\right]$ and $V[b]$ are determined by mapping the concentrations $C$ into a new variable $y$ defined as:

$$
y=\ln C
$$

According to eqn. (4), the individual points $(x, C)$ mapped into the $(x, y)$ space fit a straight line whose regression parameters are $a$ (intercept) and $b$ (slope). The variances of the regression parameters $a$ and $b$ in the $(x, y)$ space are determined as $[6,7]$ : 


$$
\begin{gathered}
V[a]=M S E\left[\frac{1}{N}+\frac{\bar{x}^{2}}{\Sigma\left(x_{i}-\bar{x}\right)^{2}}\right] \\
V[b]=\frac{M S E}{\Sigma\left(x_{i}-\bar{x}\right)^{2}} \\
M S E=\frac{\Sigma\left(y_{i}-\hat{y}\right)^{2}}{N-2}
\end{gathered}
$$

The variance of the initial concentration $V\left[C_{o}\right]$ is readily determined by returning $V[a]$ to the original $(x, C)$ space as:

$$
V\left[C_{o}\right]=\left[e^{a}\left(e^{\sigma[a]}-1\right)\right]^{2}
$$

For a given margin of error $\alpha$, the maximum distance $d_{b}$ (background distance) travelled by an ion is estimated by the point where the upper confidence limit in fig. 5 decays to a value corresponding to the uncontaminated background concentration $C_{b}$, measured in the background well $(x=420 \mathrm{~m})$. The expected background distance is estimated from eqn. (1) as:

$$
d_{b}=\frac{\ln C_{o}-\ln C_{b}}{b}
$$

To account for the variability of the parameters $C_{o}, C_{b}$ and $b$ in eqn. (9), the variance of the background distance is estimated from eqn. (9) using FOSM approximation, assuming statistical independence between $\left(C_{o}, b\right),\left(C_{b}, b\right)$, and $\left(C_{o}, C_{b}\right)$. Statistical independency between $\left(C_{o}, b\right)$ has already been demonstrated. Statistical independence between $\left(C_{b}, b\right)$ and $\left(C_{o}, C_{b}\right)$ is ensured as long as the background concentrations $C_{b}$ are not affected by the leachate contamination. Therefore [5]:

$$
V\left[d_{b}\right]=\left(\frac{\partial d_{b}}{\partial C_{o}}\right)^{2} V\left[C_{o}\right]+\left(\frac{\partial d_{b}}{\partial C_{b}}\right)^{2} V\left[C_{b}\right]+\left(\frac{\partial d_{b}}{\partial b}\right)^{2} V[b]
$$

Carrying out the derivatives:

$$
V\left[d_{b}\right]=\left(\frac{1}{b C_{o}}\right)^{2} V\left[C_{o}\right]+\left(\frac{1}{b C_{b}}\right)^{2} V\left[C_{b}\right]+\frac{1}{b^{4}}\left[\ln \left(\frac{C_{o}}{C_{b}}\right)\right]^{2} V[b]
$$


For a given margin of error $\alpha$, the background distance $d_{b, \alpha}$ is estimated from eqn. (9) and (11) as:

$$
d_{b, \alpha}=d_{b}+t[(1-\alpha), v] \sqrt{V\left[d_{b}\right]}
$$

The value $t[(1-\alpha), v]$ represents the number of standard deviations above the mean value $d_{b}$, where $t$ refers to the Student $t$ distribution with $v$ degrees of freedom. Fig. 6 shows the background distances $d_{b, \alpha}$ (eqn. 12) corresponding to different margins of error $\alpha$, for each ion. It is seen that, regardless of the ion, the background distances fall in a relatively narrow band. This seems to confirm the preponderance of advective flow over dispersive flow, as a consequence of a permeable soil stratum.

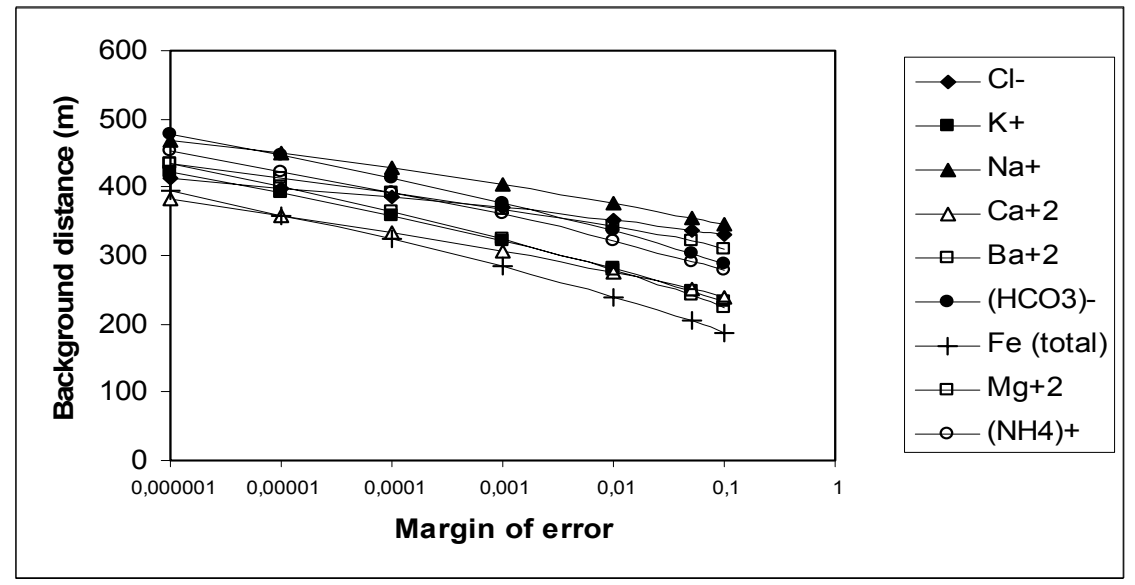

Figure 6: Variability of the background distance for each ion and different margins of error.

\section{Maximum distance travelled by the leachate}

According to fig. 6, the probability that the leachate plume exceeds a distance between $380 \mathrm{~m}$ to $480 \mathrm{~m}$ is roughly one to one million. To account more precisely for all ionic concentrations acting together in the leachate, the background distance $d_{b, \alpha}$ for each ion is plotted versus the corresponding background index $I_{b}$ defined as:

$$
I_{b}=\frac{C_{b}}{C_{o}}
$$

The background index $I_{b}$ is the ratio between the uncontaminated background concentration $C_{b}$ (measured at the background well) and the initial mean 
concentration $C_{o}$. The background index for all measured ionic concentrations ranged between 0.01 and 0.08 ( 1 to $8 \%$ of the initial mean concentration $C_{0}$ ). The only exception was the concentration of total iron, a component of the local soil mineralogy, whose $I_{b}$ value reached 0.123 .

Fig. 7 shows plots the background distance (eqn. 12) versus the background index $I_{b}$ for all ions, for margins of error of 50/100, 5/100,1/100,1/10,000 and $1 / 1,000,000$.

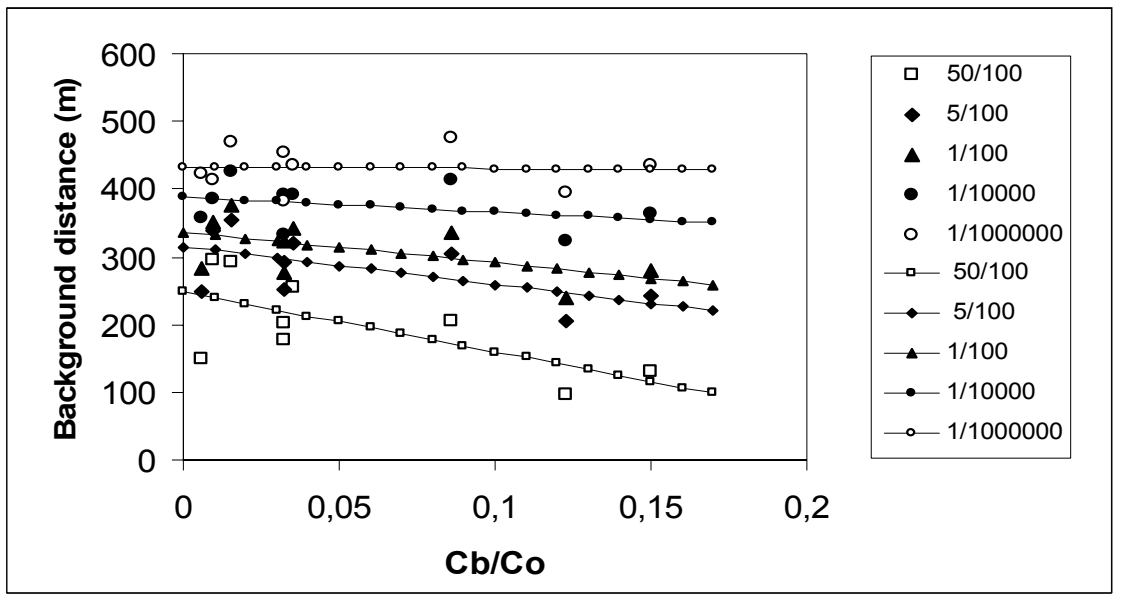

Figure 7: Background distances for different margins of error.

According to the criterion adopted in this paper, the background distance (maximum contaminated distance, accounting for all ions acting together in the leachate) is determined in fig. 7 by the point where the background index approaches zero, for a given margin of error. This is given by the intercept of the linear trend line corresponding to the margin of error considered. Fig. 7 shows that the trend lines become nearly horizontal and the corresponding data points less scattered for margins of error smaller than $1 / 10,000$. Taking this value for reference, the background distance $d_{b}=400 \mathrm{~m}$ is regarded as a safe threshold with respect to the contamination of the groundwater by the leachate. Therefore, the probability that $d_{b}=400 \mathrm{~m}$ is exceeded is less than $1 / 10,000$. By the same criterion, fig. 7 shows that the probability that the background distance exceeds $430 \mathrm{~m}$ is about one to one million. This indicates that the background well (420 $\mathrm{m}$ from the landfill) is located safely beyond the threshold value. According to fig. 7, the probability that the contamination reaches the background well is about $1 / 100,000$.

\section{Conclusions}

The motion of the contamination plume has stopped during the 15 -year period of operation of the landfill. This is confirmed by nearly stationary readings of the 
ionic concentrations in the wells located more than $100 \mathrm{~m}$ from the landfill. The leachate leak and the small soil thickness close to the landfill cause fluctuations of the ionic concentrations with time, due to seasonal variations of rain intensity and changes in the composition of the solid waste. The background distance $d_{b}=400 \mathrm{~m}$ is regarded as a safe threshold with respect to contamination of the groundwater by the landfill. The probability that this limit is exceeded is about $1 / 10,000$. Accordingly, it is concluded that the background well (located $420 \mathrm{~m}$ from the landfill) is not reached by the leachate contamination. The probability that the background well is contaminated is about $1 / 100,000$.

\section{Acknowledgments}

The financial support provided by the Brazilian Agency CNPq and by the program PROCIENCIA of the University of the State of Rio de Janeiro is acknowledged.

\section{References}

[1] Lima, J.S. Assessment of ground water contamination by the São Pedro da Aldeia landfill (in Portuguese), M.Sc. dissertation, University of the State of Rio de Janeiro, 2003.

[2] Pinto, M.J. Numerical simulation of underground contamination (in Portuguese), M.Sc. dissertation, University of the State of Rio de Janeiro, 2005.

[3] ABNT, NBR-13895. Construction of wells for monitoring and sampling, Brazilian Society for Technical Standards, 1997.

[4] CETESB 06.010. Construction of wells for monitoring groundwater, State of São Paulo Environmental Agency, 1999.

[5] Ang, A. \& Tang, W. Probability concepts in engineering planning and design - Vol I - Basic principles, John Wiley, New York, 1995.

[6] Neter, J., Wasserman, W. \& Whitmore, G.A. Applied statistics, Allyn \& Bacon Inc., Second Edition, Boston, 1982.

[7] Pacheco, M.P. \& Lima, L.S.A. A statistical criterion for interpretation of geotechnical tests, Soil and Rocks, Journal of the Brazilian Society for Soil Mechanics \& Geotechnical Engineering, V.19. n.3. pp. 177-188, 1996. 